\title{
Failure to block opiate effects of oral etonitazene with naltrexone during 24 -h choice testing
}

\author{
MINDA R. LYNCH and JOSEPH H. PORTER \\ Virginia Commonwealth University, Richmond, Virginia
}

\begin{abstract}
Thirty rats were given access to $5-\mu \mathrm{g} / \mathrm{ml}$ etonitazene and $0.1-\mathrm{mg} / \mathrm{ml}$ quinine solutions during 12 days of 24-h choice testing with a single daily 3-mg/kg naltrexone injection (Group N-CT), two 3-mg/kg naltrexone injections per day (Group 2N-CT), or a single daily vehicle (1-ml/kg saline) injection (Group Sal-CT). Control groups received either the daily naltrexone treatment or saline, and were provided with only water. Both naltrexone groups receiving choice tests displayed signs of precipitated withdrawal upon naltrexone administration. When drug solutions were replaced with water and intraperitoneal injections were terminated, spontaneous withdrawal was displayed by all three choice test groups. The results clearly demonstrate that naltrexone does not block the pharamacological properties of etonitazene in a 24-h choice test paradigm. Thus, procedures for separating taste factors from pharmacological properties of etonitazene with choice testing must employ limited access to the opiate.
\end{abstract}

One of the problems in studying oral intake of opiate drugs is that of palatability. Although animals will readily self-administer opiates via other routes, such as intravenously (Deneau, Yanagita, \& Seevers, 1969; Woods $\&$ Schuster, 1968), the bitter taste of these alkaloids in solution makes it difficult to study their pharmacological properties with oral self-administration paradigms. One approach for separating taste factors and pharmacological properties is to provide an equally bitter placebo solution (such as quinine) in choice testing with the opiate solution. Chipkin and Rosecrans (1978) and Lynch, Porter, and Rosecrans (1984) have shown that the bitter taste of methadone can be taste-balanced with a quinine solution during $24-\mathrm{h}$ choice testing. In these studies, solutions were determined to be equally palatable when chosen $50 \%$ of the time by rats given daily injections of naltrexone $(3 \mathrm{mg} / \mathrm{kg})$, a long-acting narcotic antagonist ( $24 \mathrm{~h}$ to $72 \mathrm{~h}$; Martin, Jasinski, \& Mansky, 1973; Resnick, Volvaka, Freedman, \& Thomas, 1974; Verebey, Volvaka, Mulé, \& Resnick, 1976), to block the pharmacological effects of the methadone. In the absence of naltrexone injections, rats experiencing the opiate effects of methadone developed a strong aversion to this solution.

The purpose of the present study was to apply this 24-h choice test procedure (Chipkin \& Rosecrans, 1978; Lynch et al., 1984) to the synthetic narcotic, etonitazene. Approximately 1,000 times more potent than morphine in analgesia tests (Wikler, Martin, Pescor, \& Eades, 1963), this drug can be offered in microgram concentrations. Although rats have been shown to consume substantial quantities of etonitazene under conditions of scheduleinduced polydipsia (Leander \& McMillan, 1976; McMil-

Reprint requests should be sent to Joseph H. Porter, Department of Psychology, Virginia Commonwealth University, Richmond, VA 23284. M. R. Lynch is currently at the Veterans Administration Medical Center, 800 Irving Avenue, Syracuse, NY 13224. lan \& Leander, 1976; McMillan, Leander, Wilson, Wallace, Fix, Redding, \& Turk, 1976; Meisch \& Stark, 1977), 24-h sole access (Wikler et al., 1963), cyclical exposure (Chernov, Ambrose, \& Plummer, 1968), and body-weight reduction (Carroll \& Meisch, 1079; Meisch $\&$ Kliner, 1979), demonstrations of either preference or rejection in choice test procedures are lacking.

\section{METHOD}

\section{Animals}

Fifty naive male Sprague-Dawley rats served as subjects (mean body weight $=477 \mathrm{~g}$ ). They were housed in stainless steel wire-mesh cages $(20.2 \times 24.6 \times 18 \mathrm{~cm})$, under a 12-h light-dark cycle and controlled temperature conditions. Unlimited Purina Rat Chow was made available on the floor of the cages throughout the experiments.

\section{Apparatus}

Each cage had two 250-ml water bottles mounted on the front with wire hangers. Stoppers were fitted with identical curved stainless steel drinking tubes that entered at a point equidistant from the cage sides and bottom. A laboratory-made tail-flick device was used to assess analgesia according to the procedure of D'Amour and Smith (1941). The instrument directed a $100-\mathrm{W}$ radiant heat source to the rat's tail, which was placed over a photocell plate so that reflex movement could be recorded automatically. The heat intensity was adjusted to yield a mean latency of 3.0 to $3.8 \mathrm{sec}$ in untreated rats.

\section{Drugs}

Etonitazene $\mathrm{HCl}$ was obtained from NIDA, and drinking solutions $(5 \mu \mathrm{g} / \mathrm{ml})$ were prepared fresh daily in tap water. Naltrexone $\mathrm{HCl}$ was supplied by NIDA as the racemic mixture. It was dissolved in distilled water for $3-\mathrm{mg} / \mathrm{kg}$ ip injections, in a volume of $1 \mathrm{ml} / \mathrm{kg}$. Dose determination was based on the salt. Morphine sulfate, also provided by NIDA, was dissolved in distilled water and injected subcutaneously in a dose of $5 \mathrm{mg} / \mathrm{kg}$. The injection volume was $1 \mathrm{ml} / \mathrm{kg}$, and dose again refers to the salt. Quinine capsules were obtained from Westwood Pharmaceuticals (Buffalo, NY) and were made of $300 \mathrm{mg}$ of the drug plus fillers such as lactose. Solulutions of $0.1 \mathrm{mg} / \mathrm{ml}$ (expressed as the base) were prepared daily by dissolving the contents of these capsules in tap water.

\section{Procedure}

Three separate groups of 10 rats each received single daily $3-\mathrm{mg} / \mathrm{kg}$ naltrexone injections (Group N-CT), single daily saline $(1-\mathrm{ml} / \mathrm{kg})$ in- 
jections (Group Sal-CT), or two 3-mg/kg daily naltrexone injections (Group 2N-CT). Injections were given between 1500 and $1700 \mathrm{~h}$ for Groups N-CT and Sal-CT and at 1100 and $2300 \mathrm{~h}$ for Group 2N-CT. These groups were provided with 12 days of 24-h choice tests (CT) between $5-\mu \mathrm{g} / \mathrm{ml}$ etonitazene versus $0.1-\mathrm{mg} / \mathrm{ml}$ quinine solutions. Bottles were weighed $(1 \mathrm{~g}=1 \mathrm{ml})$ and refilled with fresh solutions between 1500 and $1700 \mathrm{~h}$ each day. Body weights were also obtained at this time, and bottle positions were counterbalanced daily to control for possible position preferences. All intraperitoneal injections were begun $24 \mathrm{~h}$ before the 1st day of choice testing and were followed each day by a 10min observation period for signs of precipitated withdrawal; during the observation period, a symptom checklist derived from the descriptions of Martin, Wikler, Eades, and Pescor (1963) and McMillan et al. (1976) was used. Next, cross-tolerance testing to morphine $(5 \mathrm{mg} / \mathrm{kg} \mathrm{sc})$ analgesia was conducted $48 \mathrm{~h}$ after the last intraperitoneal injection. Baseline tail-flick latencies were obtained immediately after subcutaneous morphine administration and again 20 min later. A 10-sec cutoff was used to prevent tissue damage. Choice testing continued during the 2 days between intraperitoneal injections and analgesia testing so that crosstolerance would not be assessed during a period of withdrawal from etonitazene. Following morphine cross-tolerance testing, the etonitazene and quinine solutions were replaced with a single bottle of water for 6 days, and the rats were observed for signs of spontaneous withdrawal. Body weights were recorded for the first 5 days of those days, and fluid consumption was monitored over all 6 days.

Two additional control groups were tested during the morphine crosstolerance testing. One control group had received single daily $3-\mathrm{mg} / \mathrm{kg}$ naltrexone injections for 12 days prior to analgesia testing (Group N$\mathrm{H}_{2} 0$ ), and the other had received daily saline $(1-\mathrm{ml} / \mathrm{kg}$ ) injections (Group Sal- $\mathrm{H}_{2} \mathrm{O}$ ). Instead of etonitazene and quinine solutions, these groups had two bottles of water available for the 12 choice test days. All other aspects of the procedure were the same as for the three experimental groups.

\section{RESULTS}

\section{Choice Tests}

One rat from Group Sal-CT died after the first choice test, leaving nine rats in this group. Figure 1 presents percent etonitazene intake [milliliters of etonitazene/(milliliters of etonitazene plus milliliters of quinine) $\times 100$ ], etonitazene intake (in milliliters), and total fluid intake (milliliters of etonitazene plus milliliters of quinine) for the three groups during choice tests and water intake (in milliliters) during 6 days of observation for spontaneous withdrawal. Separate two-way analyses of variance (ANOVAs) with repeated measures across days were performed on the percent and milliliters-of-etonitazene data. Both revealed no significant main effects for groups (i.e., injection conditions) or for days; however, the groups $x$ days interactions for both analyses were significant $[\mathrm{F}(22,286)=2.19, \mathrm{p}<.01$, for percent etonitazene, and $\mathrm{F}(22,286)=2.04, \mathrm{p}<.01$, for milliliters of etonitazene]. Post hoc Tukey tests revealed a significant $(p<.01)$ decrease in percent etonitazene across the 12 days of choice testing only for Group $2 \mathrm{~N}-\mathrm{CT}$. For milliliters-ofetonitazene intake, Group N-CT showed a significant ( $\mathrm{p}$ $<.05$ ) increase from Day 1 to Day 12, Group 2N-CT showed no change, and Group Sal-CT's intake was variable, with significant differences occurring at several points.

During the 12-day choice tests, signs of precipitated withdrawal (abnormal posture, wet-dog shakes, salivation, teeth chattering, etc.) were observed upon naltrex-

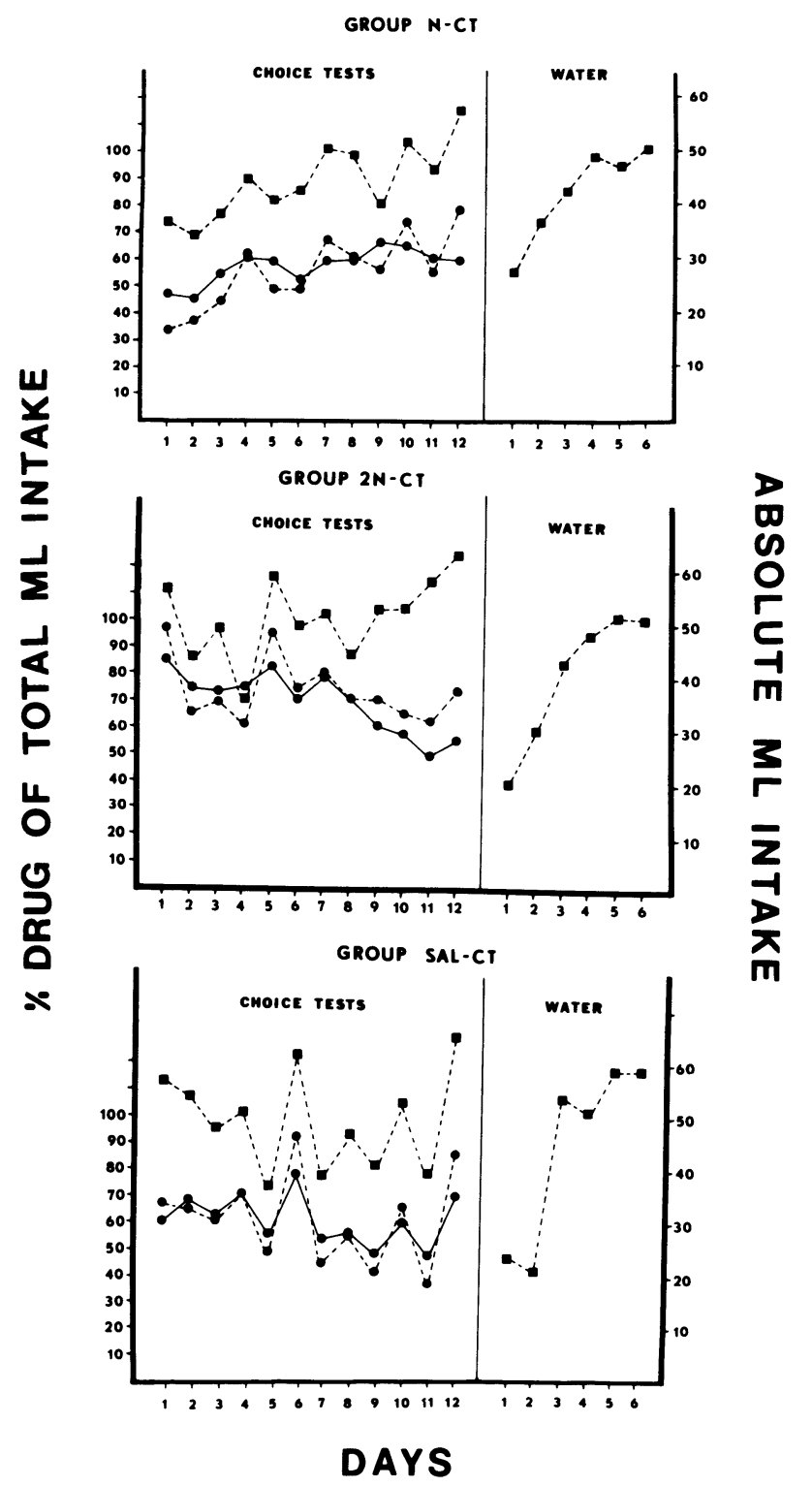

Figure 1. Total milliliter intake $(\square-\square)$, ml etonitazene $(\boldsymbol{Q}-\boldsymbol{\theta})$, and percent etonitazene $(\longrightarrow)$ of the total milliliter intake over 12 days of choice testing with etonitazene $(5 \mu \mathrm{g} / \mathrm{ml})$ versus quinine $(0.1 \mathrm{mg} / \mathrm{ml})$ and water intake (in milliliters) over 6 days of observation for spontaneous withdrawal. (Data for the 11th and 12th days were collected 1-24 and 24-48 $\mathrm{h}$ after the last intraperitoneal injection.)

one administration from Day 6 through Day 12 for Group N-CT and from Day 3 through Day 12 for Group 2N-CT. The number of rats in these two groups that displayed precipitated withdrawal varied over days, but averaged five and six, respectively.

\section{Cross-Tolerance Testing}

Data from the morphine cross-tolerance tests were converted to mean percent effect (MPE) scores [MPE = (posttest score minus pretest score)/(cutoff score minus 
pretest score) $\times 100$ ], resulting in the following group means: Group $\mathrm{N}-\mathrm{H}_{2} \mathrm{O}=54.1 \%$, Group $\mathrm{N}-\mathrm{CT}=35.5 \%$, Group 2N-CT $=17.7 \%$, Group Sal- $\mathrm{H}_{2} \mathrm{O}=44.6 \%$, and Group Sal-CT $=6.2 \%$. These percentages were then converted to arcsines to adjust for heterogeneity of variances. An ANOVA run on these arcsine values was significant $[\mathrm{F}(4,44)=3.42, \mathrm{p}<.05]$, and post hoc comparisons with the Group Sal- $\mathrm{H}_{2} \mathrm{O}$ (control) mean (Dunnett's) revealed a significant difference $(p<.05)$ only for Group Sal-CT.

\section{Spontaneous Withdrawal}

Data for the observation period for spontaneous withdrawal are shown in Figure 1 (water intakes) and in Figure 2 (body weights) for each of the three groups that underwent choice testing with etonitazene and quinine. (Repeated spillage by one rat in each of Groups Sal-CT and $2 \mathrm{~N}-\mathrm{CT}$ resulted in $\mathrm{n}=8$ and $\mathrm{n}=9$, respectively, for water intakes.) A repeated-measures ANOVA was performed on water intakes for the three groups and included total milliliter intake from Day 12 of choice testing. It revealed a significant main effect for days $[F(6,144)$ $=25.97, \mathrm{p}<.001]$, but there was no significant difference between groups and no significant interaction. A subsequent post hoc Tukey test revealed a significant $(p<$ .01) decrease in total milliliter intake over withdrawal Days 1 and 2, which recovered to prewithdrawal levels by Day 3 .

Body weights showed a more variable pattern during drug withdrawal, with Group N-CT showing only a $4 \%$ decrease from the mean 0 -h body weight at $24 \mathrm{~h}$, whereas body weights for the other two groups fell approximately $10 \%$ from this 0 -h control value at the same time point. Separate repeated-measures ANOVAs were performed on the body weights (in grams) for each group, due to differences in baseline body weights during choice testing. (Note that one rat in Group Sal-CT died during the withdrawal period, leaving $\mathrm{n}=8$ for this group.) All three $F$ values were significant: $F(7,49)=5.27, p<.001$, for Group Sal-CT; $F(7,63)=10.49, p<.001$, for Group N-CT; and F(7,63) = 12.94, p <.001, for Group $2 \mathrm{~N}-\mathrm{CT}$. Significant $(\mathrm{p}<.01)$ decreases for body weights

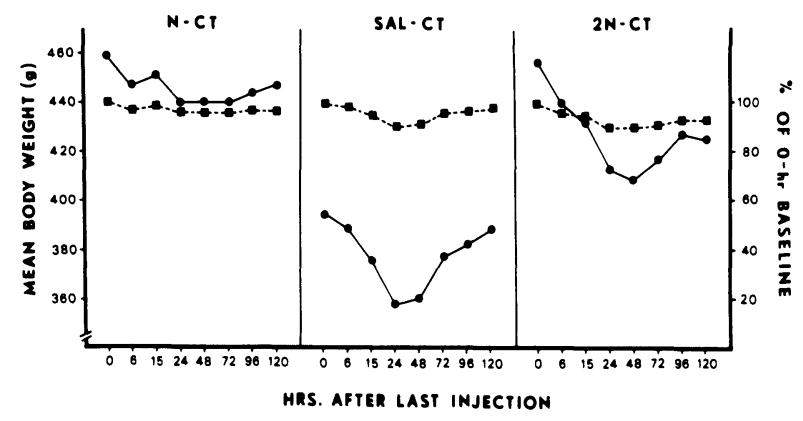

Figure 2. Mean body weight for the three groups exposed to choice testing with etonitazene versus quinine as a function of time since the last intraperitoneal injection: weight in grams $(-\infty)$ and percent of 0 -h baseline $(\square-\square)$. were observed at 24 and $48 \mathrm{~h}$ for all three groups, but only Group 2N-CT rats failed to recover to their previous prewithdrawal weights over the 5 days of measurement. No overt behavioral signs of withdrawal were evident during this time.

\section{DISCUSSION}

In spite of attempts to block the opiate effects of oral etonitazene so that unconfounded acceptance/rejection of this narcotic could be examined, the precipitated withdrawal symptoms observed in rats receiving either one (Group N-CT) or two (Group $2 \mathrm{~N}-\mathrm{CT}$ ) daily injections of naltrexone indicated a failure to induce such a blockade during 24-h drug availability. The decreases in fluid-intake and body-weight measures in the present study after removal of etonitazene, which are common symptoms of an opiate withdrawal syndrome (Leander, McMillan, \& Harris, 1975; McMillan et al., 1976; Stolerman \& D'Mello, 1981), provided further evidence of etonitazene dependence in these two groups. The results of the tail-flick data are more difficult to interpret. Whereas rats receiving subchronic naltrexone treatment only (Group N$\mathrm{H}_{2} 0$ ) may show supersensitivity to morphine analgesia (Orahovats, Winter, \& Lehman, 1953; Schultz, Wüster, \& Herz, 1979; Tang \& Collins, 1978), the tail-flick scores from groups receiving both etonitazene exposure and antagonist treatment in the present study may reflect crosstolerance and/or a continued partial blockade. The finding that only Group Sal-CT rats had significantly greater mean tail-flick latencies than the Group $\mathrm{Sal}-\mathrm{H}_{2} \mathrm{O}$ controls does indicate, however, that only this group experienced cross-tolerance as a result of opiate exposure.

Rats receiving saline injections during choice testing (Group Sal-CT) in the present study showed signs of opiate intoxication over 24-h periods, cross-tolerance to subcutaneous morphine, and indications of spontaneous withdrawal. These rats also demonstrated an erratic pattern of etonitazene intake similar to that previously reported for this drug by other researchers (Carroll \& Meisch, 1978; Chernov et al., 1968; McMillan et al., 1976; Meisch \& Stark, 1977), a pattern that may in fact be typical of oral drug consumption by addicted animals, because cyclical patterns have been noted for other drugs such as alcohol (Mello, 1973). The intake by rats of this group can be contrasted with the pronounced avoidance of a similar opiate solution, methadone, that has been demonstrated with this procedure (Chipkin \& Rosecrans, 1978; Lynch et al., 1984). This contrast is not surprising, given that etonitazene selfadministration has been easier to achieve with oral intake paradigms such as schedule-induced polydipsia (McMillan et al., 1976); however, methadone levels tend to be low with both this and intravenous procedures (McMillan et al., 1976; Oei, Singer, \& Jeffreys, 1980). The increase in milliliter intake by rats receiving two daily naltrexone injections is in agreement with earlier reports that subblocking doses of antagonists may result in paradoxical increases in drug self-administration (Goldberg, Woods, \& Schuster, 1971), whereas higher doses tend to reduce it (Goldberg et al., 1971; Meyer, Marcus, Carnathan, \& Cochin, 1976).

In conclusion, a "pure" assessment of the contribution of taste factors in the present drug-selection paradigm was not possible due to the failure of naltrexone to block etonitazene's opiate effects. Because this was the case, even with the high doses of naltrexone administered to Group 2N-CT, it does not seem possible to use choice test procedures with $24-\mathrm{h}$ access to the $5-\mu \mathrm{g} / \mathrm{ml}$ concentration of this drug that is typically offered. Therefore, although the advantages of these procedures have been outlined elsewhere (Carrol \& Meisch, 1979; Stolerman \& D'Mello, 1981), their use here is limited by the lack of an ongoing control (naltrexone-injected) group for taste. Subsequent studies (Lynch \& Porter, 1983) in our laboratory, however, have shown that naltrexone antagonism of $5-\mu \mathrm{g} / \mathrm{ml}$ etonitazene is possible with limited-access choice testing, thus enabling the study of drug preference/aversion.

\section{REFERENCES}

Carroll, M. E., \& Meisch, R. A. (1978). Etonitazene as a reinforcer: Oral intake of etonitazene by rhesus monkeys. Psychopharmacology, 59, 225-229. 
Carroll, M. E., \& Meisch, R. A. (1979). Effects of food deprivation on etonitazene consumption in rats. Pharmacology, Biochemistry and Behavior, 10, 155-159.

Chernov, H. I., Ambrose, F. I., \& Plummer, A. J. (1968). Pattern of consumption of etonitazene solutions by naive rats. Archives of International Pharmacodynamics, 175, 309-318.

ChIPKIN, R. E., \& Rosecrans, J. A. (1978). Aversiveness of oral methadone in rats. Psychopharmacology, 57, 303-310.

D'Amour, F. E., \& SMITH, D. L. (1941). A method for determining loss of pain sensation. Journal of Pharmacology and Experimental Therapeutics, 72, 74-79.

Deneau, G., Yanagita, T., \& Seevers, M. H. (1969). Selfadministration of psychoactive substances by the monkey. Psychopharmacologia, 16, 30-48.

Goldberg, S. R., Woods, J. H., \& Schuster, C. R. (1971) Nalorphine-induced changes in morphine self-administration in rhesus monkeys. Journal of Pharmacology and Experimental Therapeutics, 176, 464-471.

LeANDER, J. D., \& McMillan, D. E. (1976). Schedule-induced narcotic ingestion. Pharmacological Reviews, 27, 475-487.

LEANDER, J. D., McMillan, D. E., \& HaRRIS, L. S. (1975). Scheduleinduced oral narcotic self-administration: Acute and chronic effects. Journal of Pharmacology and Experimental Therapeutics, 195, 279-287.

LyNCH, M. R., \& PoRTer, J. H. (1983). The influence of contextual cues on subsequent preference for oral etonitazene. Society for Neuroscience Abstracts, 9, 276.

LyNCH, M. R., Porter, J. H., \& Rosecrans, J. A. (1984). Latent inhibition in the oral aversion to methadone. Pharmacology, Biochemistry and Behavior, 20, 467-472.

MARTIN, W. R., JASINSKI, D. R., \& MANSKY, P. A. (1973). Naltrexone, an antagonist for the treatment of heroin dependence: Effects in man. Archives of General Psychiatry, 28, 784-791.

Martin, W. R., Wikler, A., Eades, C. G., \& Pescor, F. T. (1963). Tolerance to and physical dependence on morphine in rats. Psychopharmacologia, 4, 247-260.

McMillan, D. E., \& LeandeR, J. D. (1976). Schedule-induced oral self-administration of etonitazene. Pharmacology, Biochemistry and Behavior, 4, 137-141.

McMillan, D. E., Leander, J. D., Wilson, T. W., Wallace, S. C., FiX, T., RedDing, S., \& TURK, R. R. (1976). Oral ingestion of narcotic analgesics by rats. Journal of Pharmacology and Experimental Therapeutics, 196, 269-179.
Meisch, R. A., \& KLINER, D. J. (1979). Etonitazene as a reinforcer for rats: Increased etonitazene-reinforced behavior due to food deprivation. Psychopharmacology, 63, 97-98.

MeISCH, R. A., \& StARK, L. J. (1977). Establishment of etonitazene as a reinforcer for rats by use of schedule-induced drinking. Pharmacology, Biochemistry and Behavior, 77, 195-203.

Mello, N. K. (1973). A review of methods to induce alcohol addiction in animals. Pharmacology, Biochemistry and Behavior, 1, 89-101.

Meyer, R. E., Marcus, R., Carnathan, G., \& Cochin, J. (1976). Narcotic blockade, length of addiction and persistence of etonitazene consumption in rats. Psychopharmacology, 47, 273-279.

OEI, T. P. S., Singer, G., \& JEFFreYS, D. (1980). The interaction of a fixed time food delivery schedule and body weight on selfadministration of narcotic analgesics. Psychopharmacology, 67, 171-176.

Orahovats, P. D., Winter, C. A., \& Lehman, E. C. (1953). The effect of $\mathrm{N}$-allylnormorphine upon development of tolerance to morphine in the albino rat. Journal of Pharmacology and Experimental Therapeutics, 109, 413-416.

Resnick, R. B., Volvaka, J., Freedman, A. M., \& Thomas, M. (1974). Studies of EN-1639A (naltrexone): A new narcotic antagonist. American Journal of Psychiatry, 131, 646-650.

SChultz, R., Wüster, M., \& Herz, A. (1979). Supersensitivity to opioids following the chronic blockade of endorphin action by naloxone. Naunyn-Schmiedeberg's Archives of Pharmacology, 306, 93-96.

Stolerman, I. P., \& D'Mello, G. D. (1981). Oral self-administration and the relevance of conditioned taste aversions. In T. Thompson, P. B. Dews, \& W. A. McKim (Eds.), Advances in behavioral pharmacology (Vol. 3, pp. 169-214). New York: Academic Press.

TANG, A. H., \& Collins, R. J. (1978). Enhanced analgesic effects of morphine after chronic administration of naloxone in the rat. European Journal of Pharmacology, 47, 473-474.

Verebey, K., Volvaka, J., Mulé, S. F., \& Resnick, R. B. (1976). Naltrexone: Disposition, metabolism, and the effects after acute and oral dosing. Clinical Pharmacology and Therapeutics, 20, 315-328.

Wikler, A., Martin, W. R., Pescor, F. T., \& Eades, C. G. (1963). Factors regulating oral consumption of an opioid (etonitazene) by morphine-addicted rats. Psychopharmacologia, 5, 55-76.

Woods, J. H., \& SCHUSTER, C. R. (1968). Reinforcement properties of morphine, cocaine and SPA as a function of unit dose. International Journal of Addictions, 3, 231-237.

(Manuscript received for publication February 5, 1985.) 